\title{
COSMO-SKYMED AO PROJECTS - USE OF HIGH RESOLUTION SAR DATA FOR WATER RESOURCE MANAGEMENT IN SEMI ARID REGIONS
}

\author{
Gerardo Di Martino ${ }^{l}$, Antonio Iodice ${ }^{l}$, Antonio Natale ${ }^{l}$, Daniele Riccio ${ }^{l}$, Giuseppe Ruello ${ }^{l}$, Ivana \\ Zinno $^{1,2}$, Youssouf Koussoube ${ }^{3}$, Maria Nicolina Papa $^{4}$, Fabio Ciervo $^{4}$ \\ ${ }^{1}$ University of Napoli “Federico II”, Via Claudio 21, 80125, Napoli, Italy \\ ${ }^{2}$ Istituto per il Rilevamento Elettromagnetico dell'Ambiente (IREA), \\ Italian National Research Council (CNR), 80124, Napoli, Italy \\ ${ }^{3}$ Departement de Geologie, UFR/SVT, \\ University of Ouagadougou, Burkina Faso \\ ${ }^{4}$ University of Salerno, via Ponte Don Melillo, 84084, Fisciano (SA) Italy
}

\begin{abstract}
In this paper we present the results of a project approved in the frame of the 2007 Cosmo-Skymed AO, devoted to use high resolution data for hydrology applications in semi-arid context. A case study was developed in Burkina Faso, a West Africa country, characterized by the alternation of intense rainy and dry seasons. In this paper we present the rationale of the project along with two of the obtained products concerning the estimation of eroded areas and the surface water recharge.
\end{abstract}

Index Terms - Synthetic aperture radar, agriculture, semi-arid regions

\section{INTRODUCTION}

According to the FAO "State of Food and Agriculture 20102011" [1], Sub-Saharan Africa is home to $26 \%$ of the world's 925 million undernourished population [1]. In the region almost $30 \%$ of the population is estimated to be undernourished due to structural and weather-related factors. In this context, the intensive and integrated use of remote sensing instruments can provide a meaningful support for identifying and managing the available resources, helping the improvement in people's living condition.

The derivation of data from remote sensing may become a key factor in the assessment and management of water resources in places where it is difficult to collect data from other sources. Anyway, the penetration of high technology in rural communities is very limited for economic, strategic and social reasons. In many low income countries even the topographic maps, at appropriate scale and resolution, may be not available.

In this paper we present the rationale and the first results of a Cosmo-SkyMed AO project devoted to use high resolution synthetic aperture radar data for calibrating hydrologic models in semi-arid regions. A case study was developed in Burkina Faso, one of the poorest countries of the world, where almost $80 \%$ of the population lives in rural areas depending from agriculture and livestock. It is characterized by the alternation of a rainy ( 3 months) and a dry (9 months) season, with extreme climate conditions (drought and floods).

Main goal of the project is to extract from the SAR data information on surface water, eroded areas, soil moisture, land cover and other physical variables that, in such a delicate ecological environment, are crucial for improving the agriculture production. The participation of local people allowed the identification of the priority, whose development involved the fusion of remote sensing and hydrology models and techniques.

The project was approved by the Italian Space Agency, that provided Cosmo SkyMed images at no cost for the users in the frame of the 2007 Cosmo-SkyMed AO. Stripmap (3m resolution) and Spotligth (1m resolution) CosmoSkyMed SAR images were acquired in the Yatenga region, in the north of the country. In Section 2 we present the studied area along with the conceptual organization of the project. Some results, mainly focused on the estimation of areas affected by erosion and of the surface water recharge are presented Section 3. The final discussion is provided in Section 4. 


\section{PROJECT RATIONALE}

Burkina Faso is a West Africa country, located in the Sahel area, characterized by strong inter-annual variability of rainfall. A long period of draught affected the area from 1970 to 2000 . The average rainfall ranges from $350 \mathrm{~mm}$ per year in the North to $1200 \mathrm{~mm}$ per year in the South of the country, according to a latitudinal gradient. The climate is characterized by a rainy season from May to September and dry season from October to April. These precipitations come from the Gulf of Guinea air moisture (monsoon). Rapid regime of rainy event causes a crusting of the soil and a significant runoff. The evaporation is about $2000 \mathrm{~mm}$ per year so that at the end of the dry season only the surface water bodies with more than $3 \mathrm{~m}$ of height survive.

We focused our attention on a test area located around the village of Bidi, almost $40 \mathrm{~km}$ north of Ouahigouya, capital of the northern Yatenga district, close to the Mali border. The project, developed with a high participation of the local people, is structured on three steps:

1. development of remote sensing models;

2. implementation of hydrologic models;

3. data fusion.

Main goal of the project is the production of innovative electromagnetic models and algorithms devoted to efficiently employ remote sensing and hydrology systems in the monitoring of the water resources in semi-arid regions. Key point for the project success was the definition of value added maps that could be understood by the beneficiaries.

\section{PROJECT RESULTS}

In this section we focus the attention on two significant activities for presenting the approach, the techniques and the results of the presented project. A first study is related on the identification areas at risk of erosion and desertification processes. The second proposed application is the estimation of the annual surface water recharge.

\subsection{Eroded soil identification}

The identification of areas prone to erosion, and the dynamic map of their evolution in time, are crucial tools for the development and optimizations of the policies to combat desertification. The production of these maps requires big efforts and high costs because of the necessary field activity. In this contest the remote sensed data may give an important contribution for the monitoring of soils prone to erosion at low cost and for wide regions.

Eroded soils are portions of land that lost their nutritional properties and their crop production potential. They are no more able to absorb and drain water, so that their humidity and, as a consequence, their dielectric constant and conductivity are almost independent by the precipitation. By comparing SAR images acquired during the rainy and the dry seasons (see Figure 1), the eroded soils do not change their reflectivity and they can be identified by change detection techniques.

In order to provide a quantitative estimation of the eroded areas, we implemented an algorithm devoted to the identification of areas whose backscattering remains weak during both the seasons.

a)
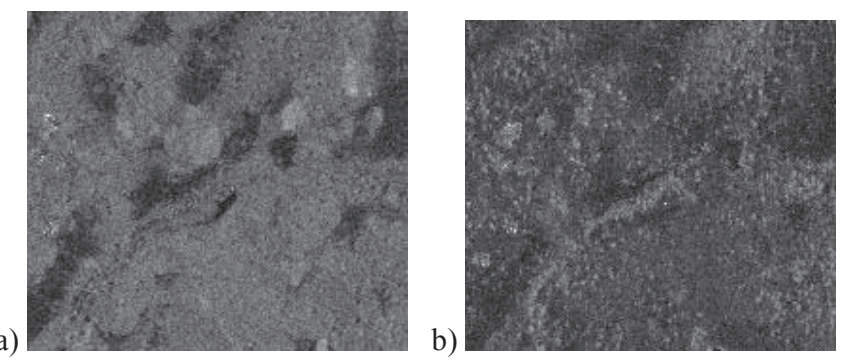

c)

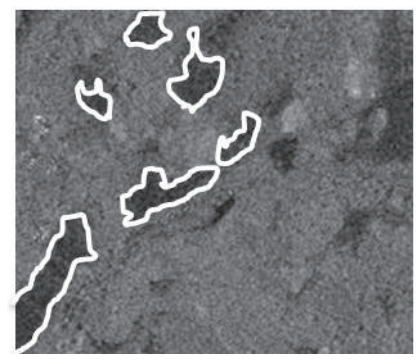

Figure 1: SAR images of the Bidi dam during the rainy (a) and dry (b) seasons. White frames (c) identify eroded soils.

False color images have been provided for helping users in the image interpretation. The goal of the work was to produce RGB maps built with the comparison of the reflectivity of the same area in different dates.

The algorithm is based on three steps:

1. Multi-time image filtering;

2. Identification of possible eroded areas;

3 . Value added map production

The De Grandi multi-time filter [4] was applied to a set of 16 images acquired between June 2010 and December 2011 in the frame of the Cosmo-Skymed AO program. The images were previously registered and calibrated thanks to the use of handmade corner reflectors built in conjunction with local farmers. In Figure $2 \mathrm{a}$ and $2 \mathrm{~b}$ it is possible to appreciate the effect of the multi-time filter on an area of 2.2 $\mathrm{km} \times 1.7 \mathrm{~km}$ in a rural area of the North of Burkina Faso, that was chosen as case study. The input Stripmap (3m of resolution) image was acquired in August, 2010, during the rainy season. The filtered image allows the identification of small cultivated fields (characterized by high signal intensity) isolated trees, and low reflectivity soils, that can be due to eroded areas, surface water or soils with limited vegetation cover. 
By crossing the image intensity of the whole set of data it is possible to identify the area in which erosion processes may have occurred. The maps derived by this technique are compared with geological maps and soil use maps in order to refine the identification of actually eroded areas. A standard Bayesian estimation algorithm allowed to determine that the $19 \%$ of the land in the considered area was in state of erosion.

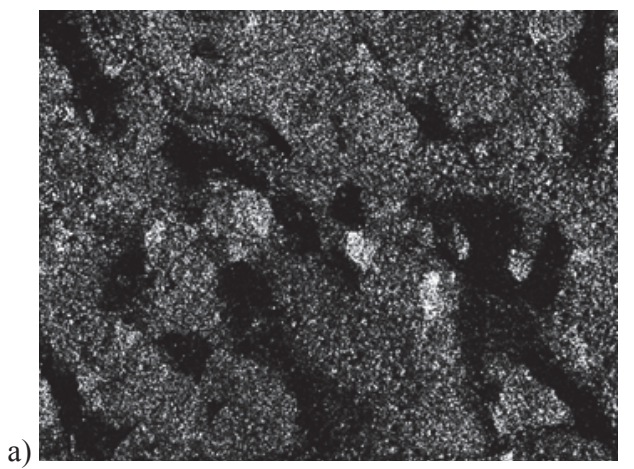

b)

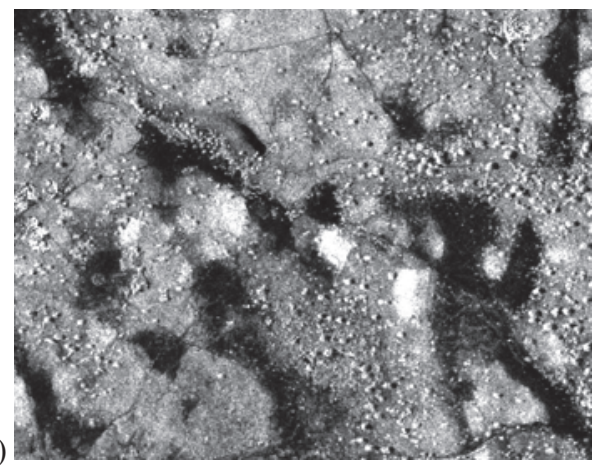

Figure 2: SAR images of the Bidi dam during the rainy (a) and dry (b) seasons. White frames (c) identify eroded soils.

The presentation of the maps to local people is crucial in order to use the results for driving soil conservation policies. Therefore, false color maps were produced for allowing an easy interpretation of the obtained results.

In order to provide a readable map for the users, we produced a map of the studied area, obtained by loading the red, green and blue channels with images relative to August 2010, August 2011 and March 2011, respectively. Along with the eroded land, other characteristics of interest for hydrology studies emerge from the result presented in Figure 3a. The interpretation of the image is supported by the label of Figure 3b.

An exhaustive interpretation of the image is beyond the goal of the paper. Anyway, it is important to note the geometry of the yellow fields located in the middle of the image and that are representative of cultivated soils. The field productivity (much higher with respect to the average value) can be due to the anti-erosion works that are built for retaining the sediment and the rich soil. Such a result suggests a further use of the SAR data for monitoring the soil conservation works in semi-arid regions.

a)

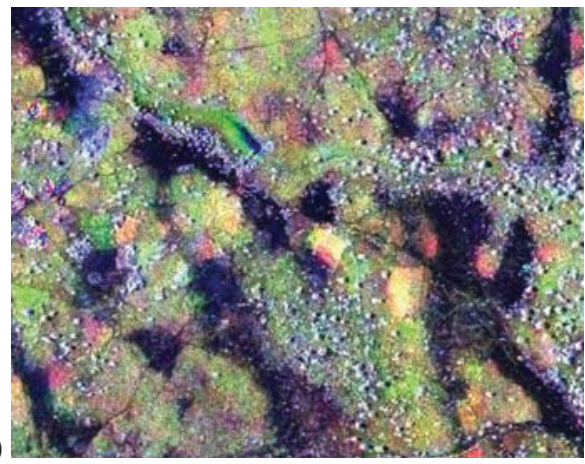

b)

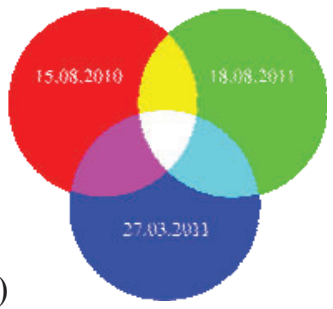

Figure 3: SAR images of the Bidi dam during the rainy (a) and dry (b) seasons. White frames (c) identify eroded soils.
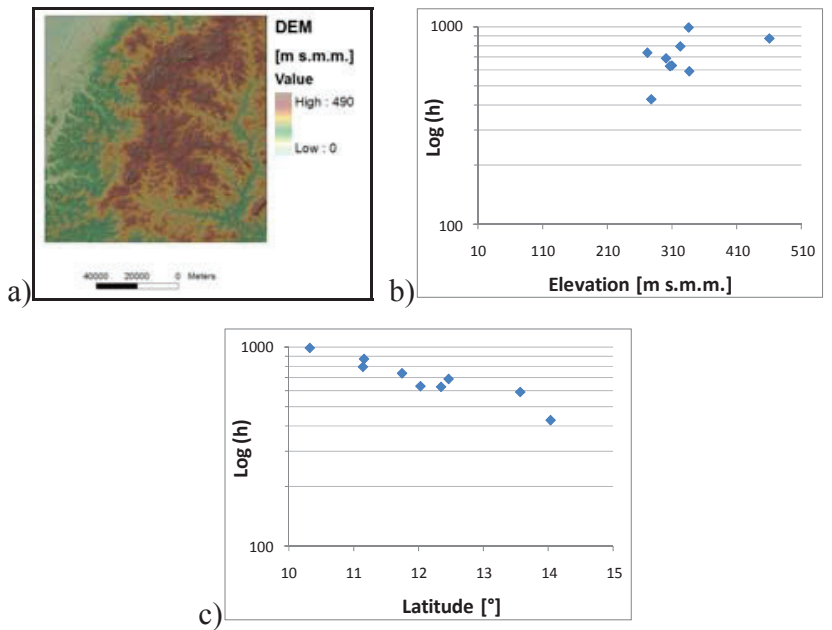

Figure 3: DEM of the study area (a); average annual rainfall versus elevation (b) and latitude (c).

\subsection{Estimation of annual surface water recharge}

As stated before, in semi-arid regions, the precipitations occur only during three months. Therefore, it is crucial to collect water in the rainy season, by the means of artificial basins, in order to irrigate the fields in the dry season. The construction of little artificial basins is usually carried out 
under the initiative of small associations of farmers. The location, design and management of the basins sometimes is not rational, for the lack of all the information needed for the design.

The best location for the construction of a new artificial basin depends on the total volume of surface water that may be collected in one year in a particular position. This element should be compared with consideration about the distance of lands to be irrigated, the value of land and other socio-economical factors. We present how to design a map showing the total amount of surface water that may be annually collected in each element of a digitalized landscape. This map may be used in GIS environment and superimposed to other maps displaying the other relevant factors. The DEM of the study area is derived by remote sensed SAR images (see Figure 2a). Series of total annual rainfall measured in 9 climatic stations of the region have been used to derive a map of rainfall spatial distribution. The average values of total annual rainfall $(h)$ have been plotted depending on the elevation $\mathrm{Z}$ (Figure $2 \mathrm{~b}$ ) and the latitude $\lambda$ (Figure $2 \mathrm{c}$ ) of the measuring stations. The following best fit equation has been derived:

$$
\log (h)=-7.9 \cdot 10^{-2} \lambda+2.9 \cdot 10^{-4} Z+3.69
$$

In Figure 3a the regional map of average annual rainfall, obtained with eq. 1, is displayed together with the DEM of the study area. The total surface water volume $(D)$ flowing in the average year, in a particular position of the landscape, may be expressed in terms of the contributing area (S) to that position, the average temperature $(t)$ and the annual rainfall $(h)$ over the contributing area. As a first approximation an empirical relationship has been employed derived for a different climatic context ([3]):

$$
\left(\overline{\frac{D / S}{1364}}\right)^{1 / 3}=\log \left(\frac{\bar{h}}{\overline{h_{0}}}\right) \quad \bar{h}>\overline{h_{0}},
$$

where $\overline{h_{0}}=64.7 t^{-0.448}$.

Specific studies are being performed at the moment to adapt the parameters of (2) to the peculiar climatic contest of Burkina Faso. The map of contributing areas, extracted by the DEM, is reported in Figure 3b. The resulting map of annually available water volumes is displayed in Figure 3c.

\section{CONCLUSIONS}

In this paper we presented some significant results of a project based on the idea that the appropriate use of remote sensing data in countries with low income and great needs is possible if a new approach that goes beyond engineering is accepted. All the project steps were characterized by the formation and participation of the final users and the used remote sensing data were provided at no cost for the local people. The hydrological model, as well as most of the remote sensing processing is developed with open source instruments, in order to guarantee the availability at almost no cost of the final results to the users. In particular, two activities have been presented in this paper for stressing the approach, the methodology and the obtained results.

An algorithm based on multi-temporal analysis of SAR data was used for providing a map of the areas prone to erosion in a rural contest, located in the North of Burkina Faso. In addition, the approach for the estimation of the best location for the construction of a new artificial basin was presented. Such an approach moves from a digital elevation model obtained from the SAR data and it evaluates the total volume of surface water that may be collected in one year in a particular position.

a)
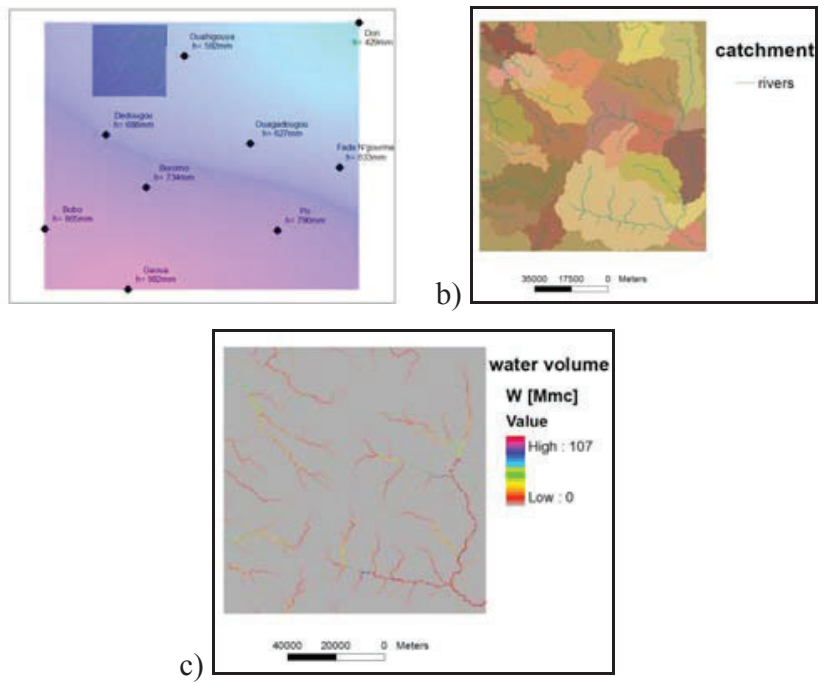

Figure 3: Regional map of the average annual rainfall (a); map of contributing areas (b) and annually available water volumes (c).

\section{REFERENCES}

[1] FAO, The State of Food and Agricolture 2010-2011, FAO, Rome, 2011.

[2] Di Martino, G., A. Iodice, D. Riccio, G. Ruello, "Imaging of Fractal Profiles", IEEE Trans. Geosci. Remote Sens., vol.48, 2010.

[3] Longobardi A., F. Rossi, P. Villani, "A Regional Statistical Analysis of Unimpaired Low River Flows and Implication for Environmental Minimum Flow Requirements", in Water resources assessment and management under water scarcity scenarios, CSDU ed., Milano, 2007.

[4] De Grandi G.F., M. Leysen, J.S. Lee and D. Schuler, "Radar Reflectivity Estimation using Multiplicative SAR Scenes of the same Target: Technique and Applications", Proc. IGARSS, 1994. 